\title{
Program Outcomes Assessment Method for Multi- Academic Accreditation Bodies: Computer Science Program as a Case Study
}

\author{
https://doi.org/10.3991/ijet.v12i05.6410 \\ Hikmat A. M. Abdeljaber \\ Prince Sattam bin Abdulaziz University, AlKharj, Saudi Arabia \\ h.abdeljaber@psau.edu.sa \\ Sultan Ahmad \\ Prince Sattam bin Abdulaziz University, AlKharj, Saudi Arabia \\ s.alisher@psau.edu.sa
}

\begin{abstract}
In educational community, assessment process focuses on learning, teaching and outcomes. It provides information for improving learning and teaching. Therefore, a well-established assessment process plays a vital role for improving program outcomes which, in turn, results in fulfilling program educational objectives. However, such a process entails setting well-defined courses learning objectives, program outcomes, and program educational objectives. In addition, an effective assessment method is needed for measuring the extent that program outcomes meet academic accreditation body criteria. This measurement is performed by mapping courses learning objectives with program educational objectives passing through program outcomes. Such mapping for just one academic accreditation body is a straightforward process and involves no complications. However, a coherent assessment method is required for multi academic accreditation bodies. The approach of mapping program outcomes across criteria of multi academic accreditation bodies is likely a promising key for addressing this issue. The proposed assessment method along with the assignments and practices used for evaluating students' performance such as quizzes and exams, and the associated action plans and recommendations for improvements are crucial steps for the overall assessment process. Findings based on the results of samples taken from a number of students for some courses of computer science program show the flexibility and effectiveness of the proposed assessment method.
\end{abstract}

Keywords-accreditation, assessment method, computer science, course learning objectives, program outcomes.

\section{Introduction}

The most important goal of every institute is to provide quality education. In order to achieve this goal every institute develops and designs better academic programs 
with experienced faculties. Quality standard depends upon the program outcomes, assessments, measurements and comparison to meet goal values and day to day changing demands of modern society. The accreditation of these programs affirms the quality of education. Accreditation is a voluntary certified mechanism for engineering programs, administered by recognized professional bodies [1]. It is one of the ways of ensuring and demonstrating the high quality of engineering education that is carried out by accreditation bodies like Accreditation Board for Engineering and Technology (ABET) and National Commission for Academic Accreditation and Assessment (NCAAA). ABET is internationally and NCAAA is Saudi Arabia kingdom based highly respected accreditation body. These accreditation bodies have adopted the concept of Outcomes-Based Education (OBE) through the adoption of Engineering Criteria 2000 (EC 2000) [2]. The common framework of implementation and assessment of outcomes-based education system is shown in Figure 1.

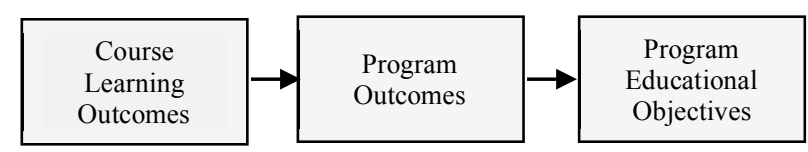

Fig. 1. The general framework of assessment of outcomes-based education system

Learning outcomes are statements that describe significant and essential learning that learners have achieved, and can reliably demonstrate at the end of a course (course learning outcomes, CLOs) or program (program outcomes, POs) [3], [4]. The CLOs contribute to the achievement of the POs. Collectively, the CLOs from all the courses in the program lead to the achievement of the POs. While outcomes are achieved results of what was learnt, objectives are intended results of instruction, curricula, programs, or activities. ABET defines program educational objectives (PEOs) as broad statements that describe what graduates are expected to attain within a few years after graduation [5]

Assessment and evaluation are two different terms. In research community, many definitions of assessment are presented [6], [7]. Assessment is a continuous process that identifies, collects, and prepares the data necessary to evaluate student outcomes (SOs) and PEOs [2]. History of assessment is discussed in [8]. Evaluation, on the other hand, is the process for interpreting the data acquired through the assessment process in order to determine how well the set of objectives and outcomes are being attained [9]. In a nutshell, assessment is a diagnostic process focuses on continuous improvement of outcome areas whereas evaluation is a judgmental process focusing on grades or scores of these areas.

In education, assessment of POs determines the degree of achievement of program learning objectives (PLOs). To assess POs, an effective assessment process is needed. The assessment process focuses on learning, teaching and outcomes. It provides information for improving learning and teaching. Therefore, a well-established assessment process plays a vital role for improving POs which, in turn, results in fulfilling PEOs. However, such a process entails setting well-defined CLOs, POs, and PEOs. Furthermore, it needs an effective method for assessing the extent that POs meet academic accreditation body criteria. This assessment is performed by mapping CLOs 
with POs and then mapping these POs with PEOs as depicted in Figure 2. Such type of mapping for just one academic accreditation body is a straightforward process and involves no complications. However, a coherent assessment method is required for multi academic accreditation bodies. To the best of our knowledge, no research work has presented a method to assess POs for multi-accreditation bodies. The process of mapping POs across criteria of multi academic accreditation bodies is likely a promising key for addressing this issue. The objective of this paper is to develop a method to assess POs by adopting the approach of mapping CLOs with POs based on the mapping criteria of multi-academic accreditation bodies. However, mapping of POs with PEOs is out of scope of this paper.

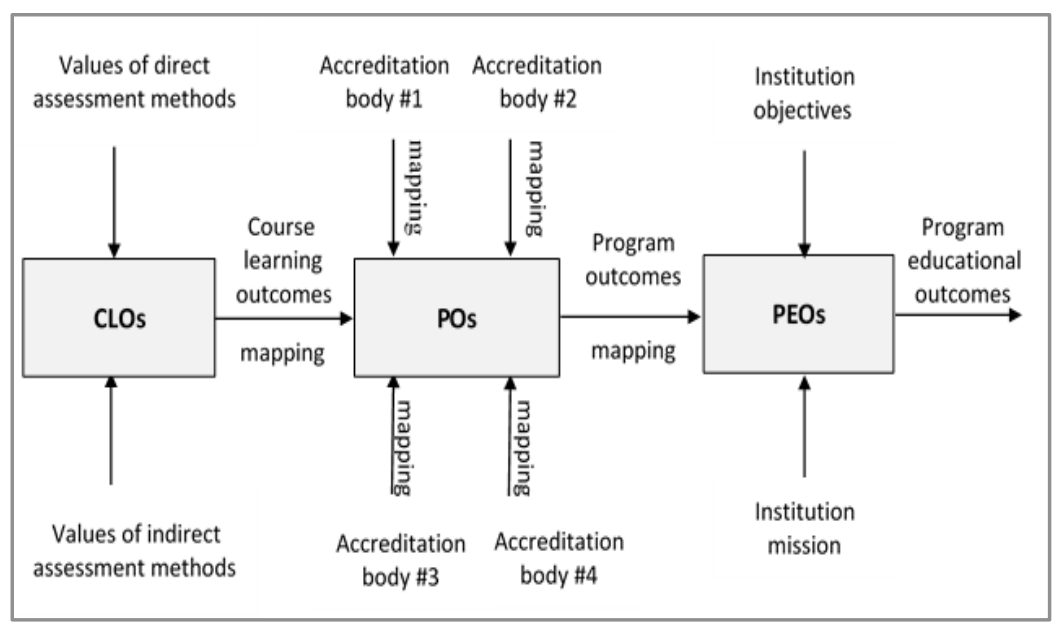

Fig. 2. Overview of the processes involved in the assessment of program outcomes

The suggested assessment method emphasizes on mapping of CLOs with current POs and then mapping these current assessed POs with another set of POs belong to a new accreditation body. The first mapping is performed only once whereas the second mapping is performed as many as number of accreditation bodies are needed for assessment. Therefore, the implementation of this method consists of two main phases. The first phase is implemented once and it assesses the current or source POs. The second phase assesses the target POs of any new accreditation body pluggable into the system. In fact, the second phase is designed to handle as many new accreditation bodies as added to the system. This handling is performed based on mapping POs of source with POs of target and comparing results. The main contribution of this paper is to develop a computing method which enables the assessment of multi-academic accreditation bodies for measuring their degree of achievement of POs by using significant mapping-based formulas.

The question arises here is how we can make use of the proposed assessment method? And the role it plays in the overall program assessment process. The answer is that the proposed assessment method along with the assignments and practices used for evaluating students' performance such as quizzes and exams, and the associated 
action plans and recommendations for improvements are crucial steps for the overall assessment process. Implementation of the method assists in discovering observations on learning outcomes involved in the assessment process. The observations are concluded from assessment values of POs that are calculated based on given assessment values of CLOs. These observations are significant information that can be interpreted as comments in a generated report helpful in improvement of learning outcomes.

In literature survey, many methods and approaches for direct assessment of POs are proposed. Matrix based structure is being used by Felder and Brent [10] and Rodriguez-Marek et al. [11] as an important promising method for assessment of outcomes by using course works. In this method, they developed a mapping between CLOs to the POs and learning objectives indicators to course objectives. Their test items are taken as the indicators for assessing learning and attainment of POs. Another methodology is being used with different mapping concept by Mason and Dragovich [12]. They collected assessment data and required mapping matrices in spreadsheet and transferred these in relational databases. SQL and data fitting through least squares are used to find out class performance of students with respect of POs. A coherent approach to the mapping, recording and assessment of POs provide evidences for accreditation that students have attained and achieved these POs [13]. Maddocks has developed a tool that enable program leaders to map and record student attainment of POs. He also explained key issues regarding assessment practices and described the design framework underpinning the development of an electronic tool to support academics in the assessment of learning outcomes.

In another work, Rifaat et al. [14] have explained an empirical study to examine the assessment of CLOs and the POs. Their description contains the assessment of the POs through the assessment of course outcomes. The assessment of each CLOs depends on weighted summation of marks obtained by students in final semester exam. The analysis of each course over four semesters shows the achievement of the CLO by cohort tends oscillate between decrease and increase during semesters.

The objective of this paper is to develop a method for assessing POs irrespective of different accreditation bodies and their special requirements. Development of such method assists in identifying deficiencies and weaknesses of learning and teaching activities and suggests action plans for continuous improvement. Computer science program is taken as a case study for implementation of this method of POs assessment. There are several benefits of this method. First, the assessment data are already being collected by most programs through exams, assignments, quizzes and projects. So there is minimum overhead associated with collection of assessment data. Second, it provides continuous assessment over time and can give a better measurement of student's knowledge. Third, the method is presented in modular-based design model, so its implementation as a software system is feasible and its maintenance becomes easier. The rest of the paper is organized as follows: Section 2 describes the proposed assessment method, Section 3 implements the method on computer science program as a case study, Section 4 analyzes findings and presents recommendations, and finally Section 5 discusses conclusion and future work. 


\section{The Program Outcomes Assessment Method}

The proposed assessment method focuses on mapping of CLOs with POs and then mapping these POs with POs of several different accreditation bodies. The method is used to assess the current POs and the result is used as a basis for assessing POs of another accreditation body the program intends to apply for. Therefore, the assessment method consists of two phases. The first phase is called source and it assesses outcomes of the program as source POs in terms of assessment values. The second phase is called target and it permits to plug-in a new accreditation body for assessing its POs as target POs. The target is assessed based on the source and the result judges whether the program meets requirements and standards of the target. This judgment assists the program's chair to decide whether the program is qualified to apply for the target accreditation body or not. The system must provide justifications and evidences in either cases. The justifications assist to take action plans for further improvement. Once again, when the program intends to apply for another accreditation body, the second phase will be only carried out with new accreditation body POs. In this novel approach, it is possible to assess as multiple accreditation bodies (POs) as needed, hence the name assessment for multi-academic accreditation bodies. The assessment of both source and target POs is presented in subsequent subsections.

\subsection{Assessment of Source Program Outcomes}

Assessment of source POs requires mapping of CLOs with source POs as shown in Figure 3. As a result, assessment values of source POs are obtained. To do this, let a program being assessed has a set of $K$ courses; $C_{1}, C_{2}, \ldots, C_{K}$. Assume that this program has a set of $J$ program outcomes; $\mathrm{PO}_{1}, \mathrm{PO}_{2}, \ldots, P \mathrm{O}_{J}$. Each course must define a finite set of CLOs. Let the set $I$ denotes the total number of CLOs in each course; $C L O_{1}, C L O_{2}, \ldots, C L O_{I}$. Note that, the set $I$ may differ from one course to another.

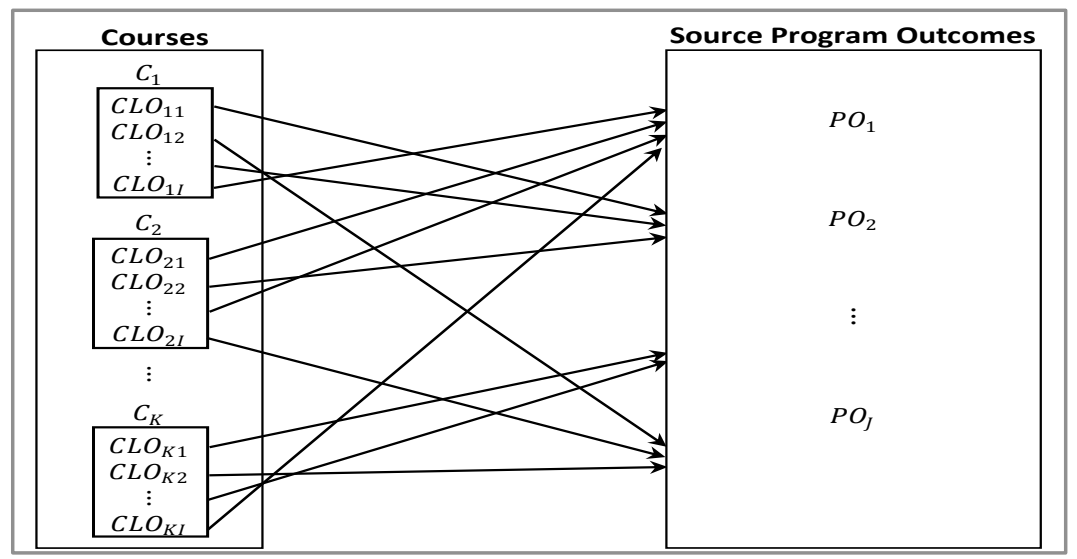

Fig. 3. Mapping course outcomes with source program outcomes 
The entities CLOs, POs, and Cs can be represented as a table of vectors of CLOs as shown in Table 1. Each row in Table 1 indicates mappings of CLOs with POs for a course C. All vectors of the same course (i.e. the same row) must have equal number of dimensions of CLOs because the same course has a fixed number of CLOs. To explain this representation, let us take an example of the course CSC1301 given in Table 2. The course has four CLOs and for this reason each of its PO is represented by a vector of four-dimensional entries $\left\langle\mathrm{CLO}_{1}, C L \mathrm{O}_{2}, C L \mathrm{O}_{3}, C L \mathrm{O}_{4}\right\rangle$. For instance, the vector $\langle 85,0,73,0\rangle$ of $P O_{1}$ means that both $C L O_{1}$, with entry value 85 , and $C L O_{3}$, with entry value 73, are mapping with $\mathrm{PO}_{1}$ but both $C L \mathrm{O}_{2}$ and $C L \mathrm{O}_{4}$, with entry values 0 , are not mapping with $P O_{1}$. In case of all entries of the vector are $0 \mathrm{~s}$ (e.g. $\langle 0,0,0,0\rangle$ of $\left.C \mathrm{LO}_{2}\right)$, this means that no CLO is mapping with the specified PO.

Table 1. Representation of courses, course learning outcomes, and program outcomes

\begin{tabular}{|c|c|c|c|c|}
\hline & $P O_{1}$ & $P O_{2}$ & $\ldots$ & $P O_{J}$ \\
\hline$C_{1}$ & $\left\langle C L O_{1}, C L O_{2}, \ldots, C L O_{I}\right\rangle$ & $\left\langle C L O_{1}, C L O_{2}, \ldots, C L O_{I}\right\rangle$ & $\ldots$ & $\left\langle C L O_{1}, C L O_{2}, \ldots, C L O_{I}\right\rangle$ \\
\hline$C_{2}$ & $\left\langle C L O_{1}, C L O_{2}, \ldots, C L O_{I}\right\rangle$ & $\left\langle C L O_{1}, C L O_{2}, \ldots, C L O_{I}\right\rangle$ & $\ldots$ & $\left\langle C L O_{1}, C L O_{2}, \ldots, C L O_{I}\right\rangle$ \\
\hline$\vdots$ & $\vdots$ & $\vdots$ & & $\vdots$ \\
\hline$C_{K}$ & $\left\langle C L O_{1}, C L O_{2}, \ldots, C L O_{I}\right\rangle$ & $\left\langle C L O_{1}, C L O_{2}, \ldots, C L O_{I}\right\rangle$ & $\ldots$ & $\left\langle C L O_{1}, C L O_{2}, \ldots, C L O_{I}\right\rangle$ \\
\hline
\end{tabular}

For each course, mapping of CLOs with POs are predefined. The achievement values of CLOs for each course are already evaluated using some standard template. These evaluated values define what are called assessment values of CLOs denoted by $C L O_{k, j, i_{a v}}$, where $k=1,2, \ldots, K$ refers to course number, $j=1,2, \ldots, J$ refers to PO number, and $i=1,2, \ldots, I$ refers to CLO number. These assessment values are assigned to the entries $C L O_{i}$ of vectors $\left\langle C L O_{1}, C L O_{2}, \ldots, C L O_{I}\right\rangle$ in Table 1 whenever mapping exists between $C L O_{i}$ and $P O_{j}$, otherwise zero value is assigned. So, the assessment values must be entered prior in the system because they are the initiating values of the assessment method. Based on assessment values of CLOs, assessment values of POs, $P O_{j_{a v}}, \forall j \in\{1,2, \ldots, J\}$, are computed by using formula 1 .

$$
P O_{j_{a v}}=\frac{\sum_{k=1}^{K} \sum_{i=1}^{I} C L O_{k, j, i a v}}{\left|C L O_{k, j, i} i_{a v \neq 0}\right|_{\forall k \forall i}}
$$

The numerator $\sum_{k=1}^{K} \sum_{i=1}^{I} C L O_{k, j, i}$ iv is the summation of assessment values of CLOs of all courses that are mapping to program outcome $j\left(\mathrm{PO}_{j}\right)$. The denominator $\left|C L O_{k, j, i_{a v \neq 0}}\right|_{\forall k \forall i}$, is the cardinality or total number of mappings from CLOs of all courses to $P O_{j}$. Formula 1 computes average of assessment values of CLOs that are mapping to $P O_{j}$. This average defines the assessment value or achievement of $P O_{j}$ denoted by $P O_{j_{a v}}$. In this way, assessment values of all source POs (i.e. $P O_{j_{a v}}, \forall j \in$ 
$\{1,2, \ldots, J\})$ are calculated and then used as basis for mapping with target POs as presented in next subsection.

To collect significant information from mappings of CLOs with source POs, trust value is introduced. Trust value defines the extent of reliability on $P O_{j_{a v}}$ and shows the degree that the assessment method trust on $P O_{j_{a v}}$ when mapping it with target $P O_{j}$. The idea is that, the greater trust value of $P O_{j}$, the more confidence and reliability is on $P O_{j_{a v}}$. It is important to mention that trust value of PO does not alter the assessment value of PO. Rather it is a sort of heuristic information useful for program reviewer in his generated report to point out which POs have been assessed moderately from those who have been assessed excessively. These extreme values may indicate deficiencies in curriculum map or lack of curriculum courses for assessing particular PO. However, trust value of each $P O_{j}$, denoted by $P O_{j t}$, is computed by using formula 2.

$$
P O_{j t v}=\frac{\left|C L O_{k, j, i_{a v \neq 0}}\right|_{\forall k \forall i}}{\left.\max \left|C L O_{k, j, i}\right|_{a v \neq 0}\right|_{\forall k \forall j \forall i}}
$$

Where $P O_{j t v}$ is the trust value of particular $P O_{j},\left|C L O_{k, j, i_{a v \neq 0}}\right|_{\forall k \forall i}$ counts the total number of mappings from CLOs of all courses to $P O_{j}$, and $\max \left|C L O_{k, j, i} a_{a v \neq 0}\right|_{\forall k \forall j \forall i}$ is the maximum of counting numbers of all $P O_{j}$, where $j=1,2, \ldots, J$.

\subsection{Assessment of Target (Accreditation Body) Program Outcomes}

The achievement of POs should be mapped with POs required by the accreditation body (TPOs). This assessment phase starts with establishing the accurate mapping for source POs with TPOs. The mapping of source POs with TPOs is shown in Figure 4. All source POs may be mapped with all or some of TPOs. The vice-versa may also possible. The result of previous subsection assessment will be used as source data in order to find status and assessment value of each TPO.

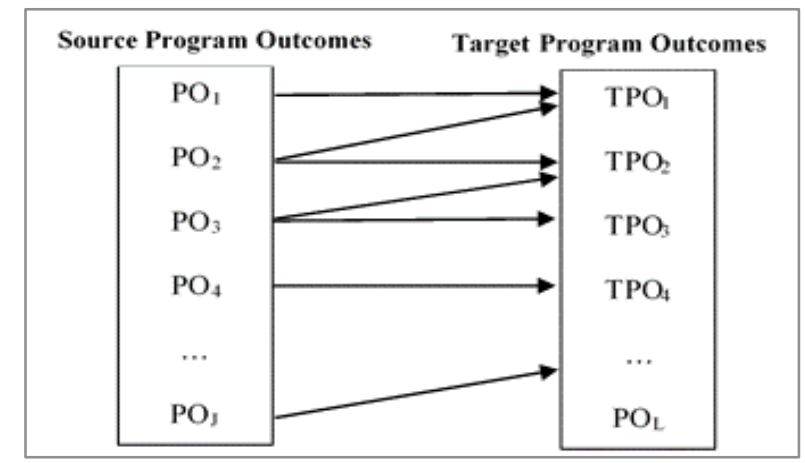

Fig. 4. Mapping source program outcomes with target program outcomes 
Suppose source POs has a set of $J$ program outcomes, $P O_{1}, P O_{2}, \ldots, P O_{J}$, with the result of achievement in percentage for each one. Let a set of $L$ targeted accreditation body program outcomes, $T P O_{1}, T P O_{2}, \ldots, T P O_{L}$, are mapped with these source POs. Now we have to assess the degree of achievement of each TPO on basis of source POs values. Based on achievement values of POs, assessment values of TPOs, $T P O_{l_{a v}}, \forall l \in\{1,2, \ldots, L\}$, are computed by using formula 3 .

$$
T P O_{l_{a v}}=\frac{\sum_{m=1}^{M} P O_{l m}}{M * L}
$$

The numerator $\sum_{m=1}^{M} P O_{l m}$ is the summation of achievement values of all source POs which are mapping to a TPO number $l\left(T P O_{l}\right)$. In denominator, $M$ is the number of all source POs which are mapping with a particular $T P O_{l}$, and $L$ is the cardinality of TPOs. The assessment result, $T P O_{l_{a v}}$, will come in percentage. The average of all $T P O_{l_{a v}}$ gives our source program outcomes achievement for this targeted accreditation body. This evaluation value used as input to make changes in curriculum, teaching methodologies and revision of POs in order to get accredited by target accreditation body.

\section{Case Study: Computer Science Program}

The present case study describes the significance and uniqueness of the proposed assessment method. For this purpose, Computer Science (CS) program of a Saudi university is taken as a case study. The program offers 31 major courses in CS and we have implemented the proposed assessment method for all courses. Here, some selected courses are used to show our assessment method. Table 2 shows assessment values of CLOs and their mapping with POs of CS program.

Table 2. Assessment values of course learning outcomes and their mapping with program outcomes

\begin{tabular}{|c|c|c|c|c|c|c|c|}
\hline \multirow{2}{*}{ 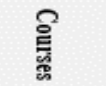 } & \multicolumn{7}{|c|}{ Source Program Outcomes } \\
\hline & $\mathbf{P O}_{1}$ & $\mathbf{P O}_{2}$ & $\mathrm{PO}_{3}$ & $\mathrm{PO}_{4}$ & $\mathrm{PO}_{5}$ & $\mathrm{PO}_{6}$ & $\mathbf{P O}_{7}$ \\
\hline CsC1111 & $(0,70,0)$ & $(90,0,0)$ & $(0,0,60)$ & $(0,0,0)$ & $(0,0,0)$ & $(0,0,0)$ & $(0,0,0)$ \\
\hline Csc1301 & $(85,0,73,0)$ & $(0,0,0,0)$ & $(0,0,0,83)$ & $(0,62,0,0)$ & $(0,0,0,0)$ & $(0,0,0,0)$ & $(0,0,0,0)$ \\
\hline $\csc 2301$ & $(0,0,0)$ & $(0,0,0)$ & $(0,0,0)$ & $(81,80,0)$ & $(0,0,60)$ & $(0,0,0)$ & $(0,0,0)$ \\
\hline $\csc 2311$ & $(0,0,0)$ & $(75,0,90)$ & $(0,0,0)$ & $(0,60,0)$ & $(0,0,0)$ & $(0,0,0)$ & $(0,0,0)$ \\
\hline $\csc 2401$ & $(0,0,0,0)$ & $(72,0,0,0)$ & $(0,0,0,60)$ & $(0,0,73,0)$ & $(0,89,0,0)$ & $(0,0,0,0)$ & $(0,0,0,0)$ \\
\hline Csc 3101 & $(0,0,0)$ & $(0,0,0)$ & $(0,0,0)$ & $(0,0,0)$ & $(0,0,73)$ & $(65,0,0)$ & $(0,82,0)$ \\
\hline $\csc 3601$ & $(0,0,0)$ & $(0,0,0)$ & $(0,0,0)$ & $(0,0,0)$ & $(0,0,0)$ & $(77,84,0)$ & $(0,0,69)$ \\
\hline $\operatorname{CsC} 4301$ & $(0,0,0)$ & $(0,0,0)$ & $(73,0,0)$ & $(0,0,0)$ & $(0,91,0)$ & $(0,0,79)$ & $(0,0,0)$ \\
\hline $\csc 4821$ & $(0,0,0,0)$ & $(0,0,0,0)$ & $(0,0,0,0)$ & $(0,0,0,81)$ & $(61,0,0,0)$ & $(0,0,79,0)$ & $(0,88,0,0)$ \\
\hline $\mathrm{CsC}_{4901}$ & $(0,83,0)$ & $(0,0,0)$ & $(0,0,67)$ & $(0,0,0)$ & $(0,0,0)$ & $(0,0,0)$ & $(82,0,0)$ \\
\hline
\end{tabular}


Based on assessment values of CLOs given in Table 2, the assessment values and their trust values of POs are calculated by using formula 1 and formula 2 respectively. This gives the result of first phase calculations as shown in Table 3. Note that the calculated assessment values of POs determine whether they meet expectations or they need some improvement. Making changes to curriculum, adopting new effective teaching methodologies, or reviewing POs are some aspects of such improvement. Note that higher assessment value of PO indicates that it meets the expectation. Usually, a determinant value is used as a satisfaction criterion to decide whether PO meets expectation or not. Some programs use determinant value $70 \%$. In this case, assessment values of POs exceed $70 \%$ only will meet the expectation. Applying this determinant value to our case study shows that all POs of CS program meet expectations except PO3 as given in Table 3. In order to improve achievement value of PO3, it is needed to be backtrack. There can be many types of reasons for the low value of PO3 or not meeting expectation by PO3. The possible reasons are improper mapping CLOs with PO3, limitation with data collection and evaluation of CLOs values, and ineffective teaching strategies.

Table 3. Assessment values and trust values of program outcomes

\begin{tabular}{|c|c|c|c|c|c|c|c|}
\hline Program Outcomes & $\mathrm{P0}_{1}$ & $\mathrm{PO}_{2}$ & $\mathrm{PO}_{3}$ & $\mathrm{PO}_{4}$ & $\mathrm{P0}_{3}$ & $\mathrm{PO}_{6}$ & $\mathrm{PO}_{7}$ \\
\hline Assessment Value (\%) & 77.75 & 81.75 & 68.60 & 72.83 & 74.80 & 76.80 & 80.25 \\
\hline Trust Value (\%) & 66.66 & 66.66 & 83.33 & 100.00 & 83.33 & 83.33 & 66.66 \\
\hline
\end{tabular}

Trust values provide additional information about the number of occurrences of CLOs mapping with each PO. Table 3 shows that PO4 has the most trust value $(100 \%)$ and PO1, PO2, and PO7 have the least trust value (66.66\%). This exhibits that large number of CLOs have been mapped with PO4 whereas small number of CLOs have been mapped with PO1, PO2, and PO7. The generated report mentions this point clearly to the program reviewer and suggests to review the mappings of curriculum courses which have least trust values as an action plan in order to improve their outcomes. Figure 5 shows the chart of assessment values and trust values of POs. 


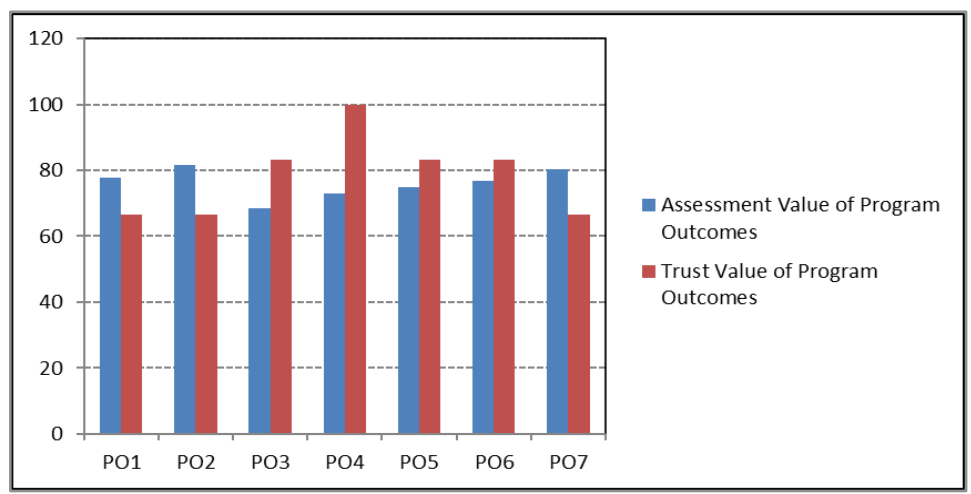

Fig. 5. Assessment values and trust values of program outcomes

In this paper, the assessment method is developed to assess POs for multiacademic accreditation bodies. Since TPOs vary from one accreditation body to another, mapping between POs and TPOs must be defined as shown in Table 4 every time you want to assess POs for a new accreditation body. For implementation aspect, every accreditation body will be taken as a plugin in the assessment method and every time will define their mapping as given in Table 4. Note that blank cells in last row (TPO6) of Table 4 means that no mappings exist between POs and TPO6 and such missing mapping will have an effect on the overall assessment value of TPOs.

Table 4. Mapping source program outcomes to target program outputs

\begin{tabular}{|c|c|c|c|c|c|c|c|c|}
\hline \multicolumn{9}{|c|}{ Source Program Outcomes } \\
\hline \multirow{7}{*}{ 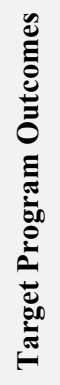 } & Mapping & $\mathrm{PO}_{1}$ & $\mathrm{PO}_{2}$ & $\mathrm{PO}_{3}$ & $\mathrm{PO}_{4}$ & $\mathrm{PO}_{5}$ & $\mathrm{PO}_{6}$ & $\mathrm{PO}_{7}$ \\
\hline & $\mathrm{TPO}_{1}$ & $\sqrt{ }$ & $\sqrt{ }$ & & & & & \\
\hline & $\mathrm{TPO}_{2}$ & & $\sqrt{ }$ & $\sqrt{ }$ & & & & \\
\hline & $\mathrm{TPO}_{3}$ & & & & $\sqrt{ }$ & $\sqrt{ }$ & & \\
\hline & $\mathrm{TPO}_{4}$ & & & & & & $\sqrt{ }$ & \\
\hline & $\mathrm{TPO}_{5}$ & & & & & & & $\sqrt{ }$ \\
\hline & $\mathrm{TPO}_{6}$ & & & & & & & \\
\hline
\end{tabular}

The second phase of the assessment method involves calculating the assessment values of TPOs. This process is performed by applying formula 3 on the assessment values of POs which are obtained from first phase calculations and the result is shown in Table 5. The summation of these assessment values of TPOs will give the overall assessment value of TPOs. In addition, the weightage for TPOs is equally divided. Since 100 is divided by number of TPOs, which is 6 , so the weight value $(100 / 6=$ $16.66 \%$ ) for each TPO is same as displayed in Table 5. 
Table 5. Assessment values of Target program outcomes

\begin{tabular}{|c|c|c|c|c|c|c|c|}
\hline Target Program Outcomes & $\mathrm{TPO}_{1}$ & $\mathrm{TPO}_{2}$ & $\mathbf{T P O}_{3}$ & $\mathbf{T P O}_{4}$ & $\mathrm{TPO}_{5}$ & $\mathbf{T P O}_{6}$ & Total \\
\hline Weight (\%) & 16.66 & 16.66 & 16.66 & 16.66 & 16.66 & 16.66 & 100 \\
\hline Assessment Value (\%) & 13.29 & 12.52 & 12.30 & 12.80 & 13.37 & 0.00 & 64.28 \\
\hline
\end{tabular}

Note that assessment value of TPO6 is 0.0 because there is no mapping for TPO6 in POs. For this reason, the overall assessment value of TPOs has got lower average (64.28\%). Lower average of assessment value of TPOs indicates that the program being assessed is not qualified enough to get accredited by the given accreditation body. Therefore, an action plan must be taken in order to improve outcomes. Here action plan suggests to review POs mappings with TPOs.

\section{$4 \quad$ Findings and Recommendations}

The results of measurement and assessment methodology are presented to the department advisory board. The following general findings are recommended for further action:

- Program outcomes that have low assessment values need backtracking to point out their deficiencies. The reasons of low values may be due to problem in proper mapping of CLOs with POs, process to evaluate CLOs values, or teaching strategies.

- Target program outcome that has zero assessment value indicates that no course outcomes map to it. This indicator shows the need to cover the PO by improving curriculum and adopting effective teaching strategies.

- Trust values are important because they show the occurrence of CLOs mapping with POs. POs that have least trust values indicate to the need of reviewing the curriculum and the mappings of curriculum courses.

- Academic programs pursue to get accreditation from national and international accreditation bodies. For this purpose, a lot of accreditation requirements must be fulfilled. This work contributes to the requirement of assessment of POs.

\section{$5 \quad$ Conclusion and Future Work}

An academic program outcomes assessment method is developed. The method aims to support program reviewer to determine whether the program being assessed can be accredited not only for a single-academic accreditation body but also for multiacademic accreditation bodies. This novel approach has adopted mapping concept and experimented real case study to prove its effectiveness. Findings based of experiments show the applicability and flexibility of the method. In future, development of some kind of intelligent automated system to implement these processes would help the team, working for getting accreditation of multi accreditation bodies. 


\section{Acknowledgment}

This work was sponsored and supported financially by a research grant from the deanship of scientific research at Prince Sattam bin Abdulaziz University "REF 2015/01/4651".

\section{$7 \quad$ References}

[1] DiBiasio D. and Mello N.A. (2004). Multilevel Assessment of Program Outcomes: Assessing a Nontraditional Study Abroad Program in the Engineering Disciplines. The Interdisciplinary Journal of Study Abroad, Vol. 10(5), pp. 237-252, Fall 2004.

[2] Engineering Accreditation Commission, Engineering Criteria 2000. (2000). Accreditation Board for Engineering and Technology, Inc. (Third Edition), Baltimore, MD.

[3] Lesch, S. (2012). Learning Outcomes, Learning Achieved by the End of a Course or Program Knowledge-Skills-Attitudes, George Brown College.

[4] Solnyshkina, M., Solovova, E., Harkova, E. and Kiselnikov, A. (2016). Language assessment course: Structure, delivery and learning outcomes. International Journal of Environmental and Science Education, Vol. 11(6), pp. 1223-1229.

[5] ABET Criteria for Accrediting Engineering Programs. (2016-2017). Available: http://www.abet.org/accreditation/accreditation-criteria/criteria-for-accreditingengineering-programs-2016-2017.

[6] Joughin, G. (2009). Assessment, Learning and Judgement in Higher Education: A Critical Review. Assessment, Learning and Judgement in Higher Education, Springer, Dordrech, Netherlands, 13-27, pp. 1-15, 2009. https://doi.org/10.1007/978-1-4020-8905-3 2

[7] Dawson, P., Bearman. M., Boud, D. J., Hall, M., Molloy, E. K., Bennett, S., and Gordon, J. (2013). Assessment Might Dictate the Curriculum, But What Dictates Assessment?, Teaching and Learning Inquiry, 1(1), 107-111. doi: 10.2979/teachlearninqu.1.1.107., 2013. https://doi.org/10.2979/teachlearninqu.1.1.107

[8] Robert, N. and Dawson, P. (2014). A contribution to the history of assessment: how a conversation simulator redeems Socratic method. Assessment \& Evaluation in Higher Education., Vol. 39(2), pp-195-204. 10p, Feb 2014.

[9] Bhatti, A. and Ahmed, I. (2015). Academic Diversity and Assessment Process for CS Program Accreditation. Scientific Research Publishing, Creative Education, Vol. 6(8), pp. 773-784. Available: http://dx.doi.org/10.4236/ce.2015.68080, May 2015.

[10] Felder, R. M. and Brent, R. (2003). Designing and teaching courses to satisfy the ABET engineering criteria. Journal of Engineering Education, Vol. 92(1), pp.7-25., [Online]. Available: http://search.proquest.com/docview/217955004?accountid=142908, Jan 2003. https://doi.org/10.1002/j.2168-9830.2003.tb00734.x

[11] Rodriguez-Marek, E., Koh, M., and Talarico, C. (2008). Connecting the dots in assessment: From course student learning objectives to educational program outcomes to ABET assessment. ASEE Annual Conf. and Exposition 2008 Conf. Proc., ASEE, Washington, D.C., June 2008.

[12] Mason, G. and Dragovich, J. (2010). Program Assessment and Evaluation Using Student Grades Obtained on Outcome-Related Course Learning Objectives. Journal of Professional Issues in Engineering Education and Practice, ISSN 1052-3928, 10/2010, Vol. 136(4), pp. 206 - 214, 2010. https://doi.org/10.1061/(asce)ei.1943-5541.0000029 
Paper-Program Outcomes Assessment Method for Multi-Academic Accreditation Bodies: Computer ...

[13] Maddocks, A. (2007). EASIMAP: a coherent approach to the assessment of learning outcomes on engineering degree programmes. Journal of Engineering education (Loughborough), ISSN:1750-0044, Date:12/01/2007, Vol. 2(2), pp:26 - 32, Jan 2007.

[14] Rifaat, N., Ben Ali, O., Al Sabhan, W. M., and Nour, M. (2012). Effective Learning Outcomes Assessment: The case of MIS Department at the UoS. Journal of Education and Vocational Research, Vol. 3(2), pp. 58-70, Feb 2012.

\section{Authors}

Hikmat A. Abdeljaber was born in Kuwait, in 1967. He received the Ph.D. degree in information sciences and technology in 2010 from the Universiti Kebangsaan Malaysia, UKM, Malaysia. He currently holds a University Assistant position at the Prince Sattam bin Abdulaziz University in Saudi Arabia, college of Computer Engineering and Sciences. He has published papers in information retrieval area and lectured in the fields of computer science and information systems for both undergraduate and graduate levels. His research interests include information retrieval, semantic web technology, data mining and machine learning.

Sultan Ahmad was born in India. He is with the Computer Science Department, College of Computer Engineering and Sciences, Prince Sattam bin Abdulaziz University, P. O. Box 151, Al-Kharj 11942, Saudi Arabia.

Article submitted 16 November 2016. Published as resubmitted by the authors 23 February 2017. 